\title{
Trends and shifts in time series of rainfall and runoff in the Gambia River Watershed
}

\author{
Vieux Boukhaly Traore ${ }^{1}$, Soussou Sambou ${ }^{1}$, Mohamed Talla Cisse ${ }^{2}$, Séni Tamba ${ }^{3}$, Sidy Fall $^{4}$, \\ Amadou Tahirou Diaw, ${ }^{5}$ Hyacinthe Sambou ${ }^{5}$, Malanda Edmond Nimy ${ }^{1}$ \\ ${ }^{1}$ Hydraulics Laboratory and Fluid Mechanics (LHMF), Faculty of Science and Technology, Department of Physics, University Cheikh \\ Anta Diop (UCAD) BP 5005, Dakar-Fann, Senegal \\ ${ }^{2}$ University of Thies, Facultty of Technological Sciences, Department of Experimental Sciences, Thies, Senegal \\ ${ }^{3}$ Thies Polytechnic School, Department of Civil Engineering, PB 10, Thies, Senegal \\ ${ }^{4}$ Office Lake Guiers Company for the Development and Operation of Lands Senegal River Delta and the Valleys of the Senegal River \\ and Falémé (SAED), Saint Louis, Senegal \\ ${ }^{5}$ Teaching Laboratory and Research in Geomatics (LERG), Faculty of letters and Social Sciences, Department of Geography, \\ University Campus of Polytechnic High School of Dakar BP 5005 Dakar-Fann, Senegal
}

\section{Email address: \\ vieuxboukhalytraore@yahoo.fr (V. B. Traore)}

\section{To cite this article:}

Vieux Boukhaly Traore, Soussou Sambou, Mohamed Talla Cisse, Séni Tamba, Sidy Fall, Amadou Tahirou Diaw, Hyacinthe Sambou, Malanda Edmond Nimy. Trends and Shifts in Time Series of Rainfall and Runoff in the Gambia River Watershed. International Journal of Environmental Protection and Policy. Vol. 2, No. 4, 2014, pp. 138-146. doi: 10.11648/j.jjepp.20140204.13

\begin{abstract}
For several decades, climate change and climate variability issues and their impacts on the hydrological regime of rivers have constituted a major topic for hydroclimatological sciences research and water resources planning policies. Understanding of these issues needs enough long time series of rainfall and runoff data covering a large period, and a comprehensive diagnosis of the existing trends and shifts in these time series of data. This can be done by applying robust statistical tests to relevant rainfall and runoff time annual series. The aim of this paper is to highlight the effect of climate change in the Gambia River Basin and its impacts on the availability of the water resources of this basin. To reach this objective, we have selected runoff time series of the Gambia River Basin at Mako, Kedougou Diaguéri streamgauges and rainfall time series at Koulountou's rain gauge. Statistical tests for shift detection presented in the Khronostat software, such as Pettit, Hubert and Buishand ellipse tests are first used, Mann Kendall test for annual trend are then applied to check whether trends exist or not in these times series. When the null hypothesis of no trend is rejected, the non parametric Sen's test is then applied to validate the Mann Kendall trend test and to estimate the magnitude of the trend and its direction. Tests for homogeneity show an increasing shift for rainfall time series of Koulountou raingauge and for runoff time series of Mako and Diaguéri and a decreasing shift for Kedougou streamgauge. According to the Mann Kendall trend test, there is an upward trend for Koulountou rainfall time series, and Mako and Diaguéri runoff time series, and a downward trend for Kedougou annual runoff time series. The Buishand ellipse and the Hubert test indicate generally the same year of the beginning of the shift. Interesting perspectives for decision makers in evaluation and precise management of water resources and water projects in the Gambia River basin are offered as well.
\end{abstract}

Keywords: Climate Variability, Hydrometeorological Data, Statistical Hydrology, Water Resources, Watershed, Gambia River, Management, Decision Making, Country Planning

\section{Introduction}

Climate change and climate variability have a great impact on economic and social human activities. It is by this way a challenge for scientific research in recent years $[1,2,3]$. Climate can basically be defined as the average weather conditions of a particular neighborhood observed over a period of time [4]. Climate change and variability result in significant changes to the decline in rainfall, in piezometric level and the fall of the flows of rivers [5, 6]. Such a disruption in rainfall as runoff regimen, can directly or indirectly penalize development projects related to water, 
such as agriculture [7, 8]. It can also affect the good functioning of arrangements previously made to these climate changes [9,10-11,12]. Thorough knowledge about the long-term variability and trends of rainfall is seen as a major concern in environmental science because of the extreme vulnerability of the environment where the climate can be broadly defined by an annual rainfall [13]. To characterize these climatic fluctuations, the statistical analysis of time series of rainfall/runoff at different sites on possible longer periods is essential and uncontested to better seek to locate them in the chronology available $[11,14,15]$. Statistical analysis involves studying past events, the characteristics of processes (rainfall, runoff) to define the probabilities of future occurrence $[16,17,18]$. This prediction is based on fitting the act of probability to the empirical frequencies of past observation [16]. Analysis of the frequency of rain predicts the characteristics in terms of quantiles, return period, and response time of the watershed [16]. It quantifies the extent of flooding and takes the decisions necessary for the drainage of rainwater to mitigate the impact of these events [16]. Statistical analysis indicates an increasing trend of the mean annual precipitation and the existence of some break points in the data series $[19,20]$. Annual rainfall is an essential component in the water budget [20].Most of water resources projects are designed based on the historical pattern of water availability and demand, assuming constantly climatic behavior [20,21]. So, any change in climatic behavior has a big influence in the precipitation regimen [20,22].The existence of an increasing or decreasing trend in hydrological time series can be explained by changes in the factors that influence precipitation [20, 23, 24].The analysis of long time series of annual/ monthly rainfall can help put the current drought in historical perspective and thus enjoy the alternating wet and dry periods to better characterize the current annual rainfall deficit [25,26]. It shows the existence of significant relationships of dependency [27]. It also reveals a strong tendency for a dry year is followed by another dry year [25, 27]. Assessing trends in rainfall characteristics based on past records together with the perception of the local community is essential to develop adaptation strategies [28].The Ecosystem management requires the collection of data to define one or more quantitative indicators whose evolution is typically observed year to year or month by month [29]. Today, most of these information systems exist on a relatively short period of time and therefore give a vision of the "short term" evolution. The difficulty is thus to appreciate any trend in the dynamical process and/or detect significant changes which would allow to define efficient strategies for ecosystem management or to detect the impact of some human activities on the behavior of natural ecosystem [29]. To resolve this difficulty, long time series data are needed but sometimes this is not sufficient to detect changes and trends in climate/hydrological variables, [30,31]. Some of the reasons of these difficulties are related to data availability and quality. To ensure the quality of the results and conclusions on the study of climate change and its impacts, the check of data quality is a preliminary and mandatory task $[32,33]$. Reliable measurements of climate data are the essential foundation for quantitative climate analyses. Unfortunately, there are several factors that affect the quality of climate data and these factors must be understood and considered both for scientists and climate analyzes [17]. Although there are universally accepted/recommendations for instrument installation and observations, the measurement practices and instruments may differ from station to station in a given country, and also there may be changes in an individual station from time to time. As a result, these factors cause variations in station time series [17]. There are today several methods and tools for detecting trends and breaks in the hydro climatic series [34]. Statistical analysis requires methodological rigor and should lead to conservative interpretations [34,35].That is why the choice must be made by the identification of tools or methods that can accurately highlight all the events related to climate variability and change and their impact on water resources to ensure prediction $[36,37,15]$. In this paper, we focus on the Gambia River basin on the west coast of Africa. Tests for detecting trends and shifts have been applied to runoff time series of this watershed at Mako, Kédougou, Diaguéri's streamgauges and rainfall time series at Koulountou's raingauge. The Khronostat software was used to search for potential interruptions by Pettitt, Buishand and Hubert's methods [38]; Mann Kendall test and Sen.'s estimator of slope are used to solve the question of trends detections and its directions and magnitudes. The aim of this study is to check trend and shift in the time series of rainfall and runoff of Gambia river basin to measure the effect of the climate change and variability and its direct impact on water resources. The methods used to identify a shift or trend in the time series are described in flowing section and the conclusions are presented in the last section.

\section{Materials and Methods}

\subsection{Study Area and Data}

The Gambia River Basin (figure1) is shred by three countries: Gambia, Guinea and Senegal. It is $1150 \mathrm{~km}$ long which 205 in Guinea, 485 in Senegal, 460 in Gambia and covers an area of more than $60000 \mathrm{~km} 2$. The basin is located on the western coast of Africa, in latitude $11^{\circ} \mathrm{N}$ in the Fouta Djallon to $15^{\circ} \mathrm{N}$ in the south-eastern ferlo full tropics wet; longitude $11^{\circ} 13 \mathrm{~W}$ (Fouta Djallon) $16^{\circ} 42 \mathrm{~W}$ ( Banjul, mouth). It is subject to the influence of the monsoon in the Gulf of Guinea and knows a unimodal rainfall; the dry season is the northern winter is increasingly long as and as one goes north. Meanwhile the amount of precipitation decreases from over $1500 \mathrm{~mm}$ in the highlands of the Fouta Djallon to $500 \mathrm{~mm}$ in southern Ferlo; average and maximum temperatures rise and evaporation and insulation. Gambia crosses the Senegalese border upstream Kédougou where it is controlled by the Kédougou's streamgauge. Just downstream, the Gambia 
receives watershed Diaguéri, controlled streamgauge of Diaguéri. The river begins its crossing of the North Fouta Djallon by a large loop in the middle of which stands stream gauge of Mako ; it enters the plates of continental terminal to its mouth it receives on his left watershed Koulountou controlled by the streamgauge of NKNP (Niokolo Koba National Park). Data used in this study are rainfall at Koulountou's raingauge, and runoff at Mako, Diaguéri and Kédougou's streamgauges. These data are acquired from the database of OMVG (Organization for the development of the Gambia River) shared by the countries of Guinea, Gambia and Senegal. The periods extending from 1974 to 2006 for Koulountou's raingauge; 1974 to 2000 for Mako stream- gauge; 1974 to 2008 for Diaguéri streamgauge and 1970 to 2006 for Kedougou streamgauge have been selected. We present in the (table1), geographic coordinates, catchment areas, database periods, years with missing data, average and standard deviations of the measurement stations of our study zone.

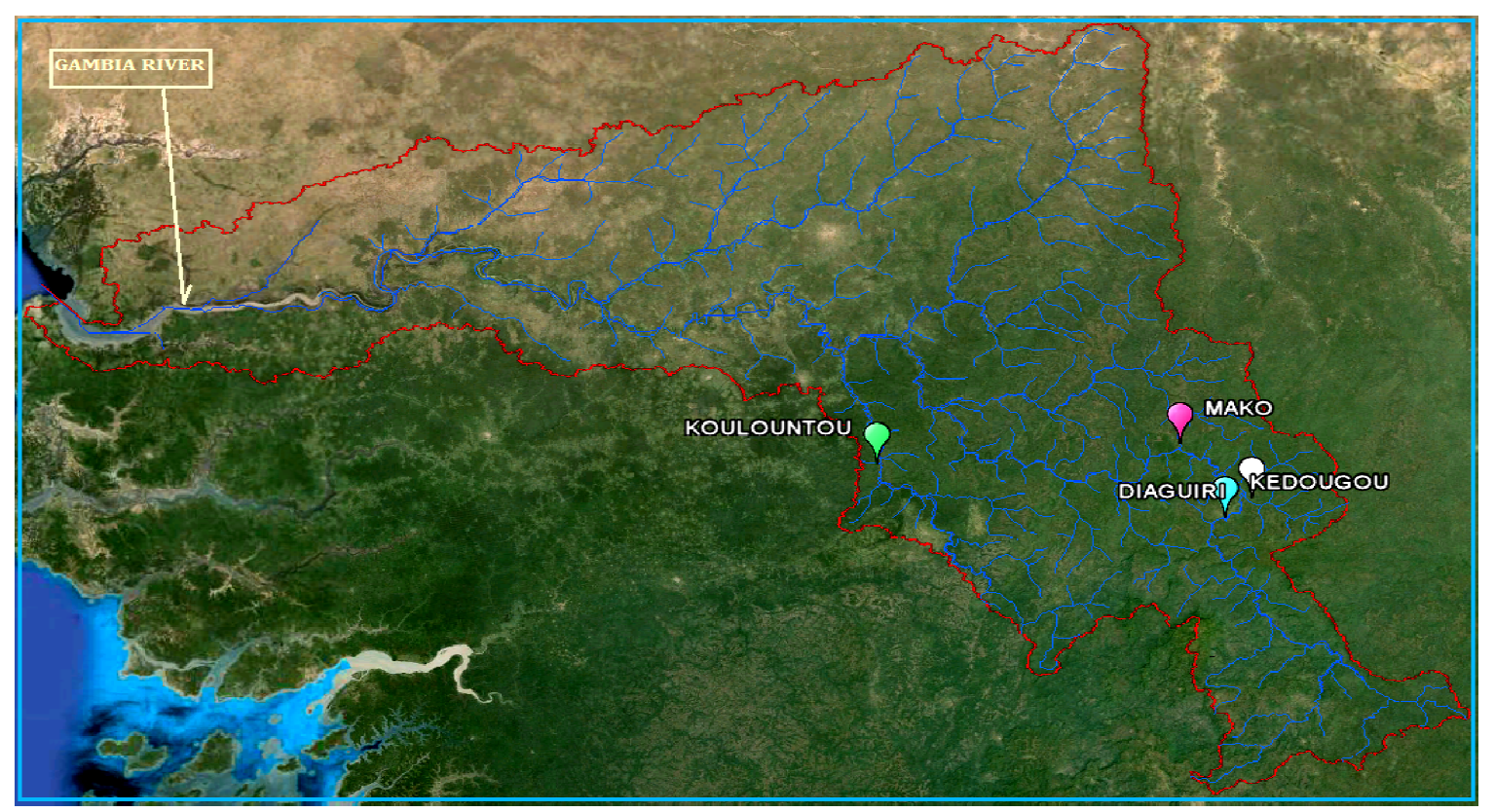

Figure 1. Gambia River basin

Table 1. Geographical locations and hydrometeorological database for five stations used in the study.

\begin{tabular}{|c|c|c|c|c|}
\hline Stations & Koulountou & Mako & Diaguiri & Kedougou \\
\hline Latitude & $12^{\circ} 47 \mathrm{~N}$ & $12^{\circ} 52 \mathrm{~N}$ & $12^{\circ} 38 \mathrm{~N}$ & $12^{\circ} 33 \mathrm{~N}$ \\
\hline Longitude & $13^{\circ} 29 \mathrm{~W}$ & $12^{\circ} 21 \mathrm{~W}$ & $12^{\circ} 05 \mathrm{~W}$ & $12^{\circ} 11 \mathrm{~W}$ \\
\hline Catchment area & $5350 \mathrm{Km}^{2}$ & $10450 \mathrm{Km}^{2}$ & $1010 \mathrm{Km}^{2}$ & $7550 \mathrm{Km}^{2}$ \\
\hline Variables used & rainfall & runoff & runoff & runoff \\
\hline Database period & $1974-2006$ & $1974-2000$ & $1974-2008$ & $1970-2006$ \\
\hline Years with missing data & 1994,1995 & ---------- & -------- & ------- \\
\hline Average & 75.80 & 86.7 & 9.20 & 72.55 \\
\hline Standard deviation & 36.79 & 28.27 & 10.34 & 25.78 \\
\hline
\end{tabular}

\subsection{Statistical Shift Detection Methods}

A shift is a change in the probability distribution function of the variable describing the evolution of a hydrological occurring at a given date $[3,39]$. The existence of a shift in a time series allows detecting a change in the mean of this time series. There are various methods in detecting inhomogeneity $[28,40]$. The methods used to detect a shift in this paper are Pettitt test, Buishand test and the segmentation procedure of Hubert. These methods are commonly used in the climatology to detect inhomogeneities in the meteorological time series [17, 41, 42]. The null hypothesis ( $\mathrm{H} 0)$ that is tested is that there is no shift in the time series. The significance level that was used is $\alpha$ equal to $5 \%$. These tests are nonparametric: i.e. that they do not require knowing the probability distribution of the hydrological variable. They allow determining easily the discontinuities in the precipitation or runoff series. Their choice in this study is justified by the robustness of their procedure and the fact they have already been successfully applied to hydrometric series observed in Sudano-Sahelian Africa several authors [6]. We shortly present them in the following:

\subsubsection{Pettitt Test}

The Pettitt test is a non - parametric one [43]. The absence of shift in the time series $\left(\mathrm{x}_{\mathrm{i}}\right)$ of size $\mathrm{N}$ is the null hypothesis. The use of the test supposes that for any time

$t$ with a value between 1 and $N$, the two time series $\left(x_{i}\right)$ for $\mathrm{i}=1$ to $\mathrm{t}$ and for $\mathrm{j}=\mathrm{t}+1$ to $\mathrm{N}$ belong to the same population. The basis of this test is the following [20]: (i) 
the studied series is divided into two sub-samples of sizes $\mathrm{m}$ and $\mathrm{n}$ respectively; (ii) the values of the two samples are grouped and arranged by increasing order; (iii) the sum of the ranks of the components of each sub-sample in the total sample is then calculated by (1); (iv) a statistic, $U_{t}$, is defined using the two sums thus obtained in order to assess whether the two samples belong to the same population given by (2).

$$
\begin{gathered}
D_{i, j}=\operatorname{sgn}\left(x_{i}-x_{j}\right)=\left\{\begin{array}{ccc}
1 & \text { si } & x_{i}-x_{j}>0 \\
0 & \text { si } & x_{i}-x_{j}=0 \\
-1 & \text { si } & x_{i}-x_{j}<0
\end{array}\right. \\
U_{t, N}=\sum_{i=1}^{t} \sum_{j=t+1}^{N} D_{i, j}
\end{gathered}
$$

Pettitt proposed, "for the test of null hypothesis H0: 'no change' against alternative hypothesis H1: 'change', the use of the statistic given by (3):

$$
\mathrm{K}_{\mathrm{N}}=\max \left|\mathrm{U}_{\mathrm{t}, \mathrm{N}}\right|
$$

for, $\mathrm{t}=1$ to $\mathrm{t}=\mathrm{N}-1$

If $\mathrm{k}$ is the value of $\mathrm{K}_{\mathrm{N}}$ taken on the studied series, under the null hypothesis, then the significance probability associated with the value $\mathrm{k}$ of $\mathrm{K}_{\mathrm{N}}$ is approximately given by (4)

$$
\operatorname{Prob}\left(\mathrm{K}_{\mathrm{N}}>K\right) \approx 2 \exp \left[-6 \mathrm{~K}^{2} /\left(\mathrm{N}^{2}+\mathrm{N}^{3}\right)\right]
$$

If Prob $(\mathrm{K}>\mathrm{k})<\alpha$, for a significance level $\alpha$, then the null hypothesis is rejected, and an estimation of the date of the break is provided by the moment $t$ defining the maximum in absolute terms of the $\mathrm{U}_{\mathrm{t}, \mathrm{N}}$ variable [3]

\subsubsection{Buishand U Statistic}

The Buishand test is Bayesian procedure applied under the assumption that the studied series is normally distributed [44]. Then, the Buishand U statistic is defined by (5):

$$
\mathrm{U}=\frac{\sum_{\mathrm{K}=1}^{\mathrm{N}-1}\left(\mathrm{~S}_{\mathrm{k}} / \sigma_{\mathrm{x}}\right)^{2}}{\mathrm{~N}(\mathrm{~N}+1)}
$$

Where the terms $S_{\mathrm{k}}$ and $\sigma_{\mathrm{x}}$ are the partial sum and the standard deviation of the given $\operatorname{series}\left(\mathrm{x}_{\mathrm{i}}\right)$ that tests for homogeneity can be based and they are respectively given by (6) and (7); $\overline{\mathrm{x}}$ is the average given by (8):

$$
\begin{gathered}
\mathrm{S}_{\mathrm{k}}=\sum_{1}^{\mathrm{N}}\left(\mathrm{x}_{\mathrm{i}}-\overline{\mathrm{x}}\right) \\
\sigma_{\mathrm{x}}^{2}=\sum_{1}^{\mathrm{N}}\left(\mathrm{x}_{\mathrm{i}}-\overline{\mathrm{x}}\right)^{2} / \mathrm{N} \\
\overline{\mathrm{x}}=\frac{1}{\mathrm{~N}} \sum_{1}^{\mathrm{N}} \mathrm{x}_{\mathrm{i}}
\end{gathered}
$$

The null hypothesis of the statistical test is the absence of shift in the series. In the case of rejection of the null hypothesis, no estimation of the date of the shift is proposed by this test [28]. In addition to these different procedures, the building of a control ellipse makes it possible to analyze the homogeneity of the (xi) series. Under the null hypothesis assumption, the $S_{k}$ variable, defined above, follows a normal distribution with a zero mean and a variance equal to (9):

$$
\sigma^{2}=\frac{1}{N} K(N-K)
$$

With, $\mathrm{k}=0$ to $\mathrm{N}$.

This control ellipse was used here to estimate visually the importance of the deviations under the null hypothesis of the homogeneity of the series [45]. It is consequently possible to define confidence limits including the series of the $S_{k}[46]$.

\subsubsection{Hubert Segmentation}

Hubert's segmentation procedure detects the multiple shifts in time series [47]. It provides, thanks to a specific algorithm, one or several break dates (or possibly none).The principle is to cut the series into $\mathrm{m}$ segments $(m>1)$ such that the calculated means of the neighboring sub-series significantly differ. To limit the segmentation, the means of two contiguous segments must be different to the point of satisfying Scheffe's test. The procedure gives the timing of the shifts. Giving a $\mathrm{m}^{\text {th }}$ order segmentation of the time series, $\mathrm{i}_{\mathrm{k}}, \mathrm{k}=1, \mathrm{~m}$, the rank in the initial series of extreme end of the $\mathrm{k}^{\text {th }}$ segment (with $\mathrm{i}_{0}=0$ ), the following are defined by (10) and (11):

$$
\begin{gathered}
\overline{\mathrm{x}_{\mathrm{k}}}=\frac{\sum_{\mathrm{i}=\mathrm{i}_{\mathrm{k}-1}+1}^{\mathrm{i} \mathrm{i}_{\mathrm{j}}} \mathrm{x}_{\mathrm{j}}}{\mathrm{i}_{\mathrm{k}}-\mathrm{i}_{\mathrm{k}-1}} \\
\mathrm{D}_{\mathrm{m}}=\sum_{\mathrm{k}=1}^{\mathrm{k}=\mathrm{m}} \sum_{\mathrm{i}=\mathrm{i}_{\mathrm{k}-1}+1}^{\mathrm{i}=\mathrm{i}_{\mathrm{k}}}\left(\mathrm{x}_{\mathrm{i}}-\overline{\mathrm{x}}_{\mathrm{k}}\right)^{2}
\end{gathered}
$$

$D_{m}$ is the quadratic deviation between the series and the segmentation. For a given segmentation order, the algorithm determine the optimal segmentation of a series that is such that the deviation $D_{m}$ is minimal. This procedure can also be interpreted as a stationary test, the null hypothesis being the studied series is non-stationary. If the procedure doesn't produce acceptable segmentations of order bigger or equal to two, the null hypothesis is accepted $[48,49]$.

\subsection{Statistical Trend Detection Methods}

Trend is the tendency of a phenomenon over a fixed period; it can vary according to the reference temporal window. It is well known that the time series data required for trend analysis should be random and/or non-persistent [41]. One of problems in the analysis and interpretation of trends in hydrological data is the confounding effect of serial dependence [24]. Furthermore, in the presence of positive serial correlation, the non-parametric test could signify a significant trend due to random effects of the data series [50]. Among the tests to detect (linear) trend in time series the most used are Mann Kendall and Sen's estimator of slope because of theirs simplicity and robustness [51]. The null hypothesis (H0) that is tested is that there is no trend in the time series. The significance level that was used is $\alpha$ equal to $5 \%$. 


\subsubsection{Sen's Estimator of Slope}

This test is applied in cases where the trend is assumed to be linear, depicting the quantification of changes per unit time [52]. This method could be used with missing data and remain unaffected by outliers or gross errors [24, 50]. It allows also estimating the magnitude and direction of the trend [53]. The $\mathrm{N}$ values of slopes $\mathrm{P}_{\mathrm{ij}}$ for $\mathrm{n}$ observations are calculated by:

$$
P_{i j}=\frac{X_{j}-X_{i}}{j-i}
$$

Where $\mathrm{x}_{\mathrm{j}}$ and $\mathrm{x}_{\mathrm{i}}$ are data values at times (or during time periods) $\mathrm{j}$ and $i$, respectively, and where $\mathrm{j}>\mathrm{i}$ for, $\mathrm{i}=1$ to $\mathrm{i}=$ $n$; and $\mathrm{j}=\mathrm{i}+1$ to $\mathrm{j}=\mathrm{n}$

After slopes computations, the $\mathrm{N}$ values of slope are algebraically classified in ascending order (there included the null value if there's any) and median of these $\mathrm{N}$ values of slope noted $\mathrm{P}_{\mathrm{M}}$ which is Sen's estimator of slope, is estimated depending on whether $\mathrm{N}$ is odd or even by (13):

$$
P_{M}= \begin{cases}\frac{P_{N+1}}{2} & \text { if } N \text { is old } \\ \frac{1}{2}\left(\frac{P_{\frac{N}{2}}}{2}+\frac{\left.P_{\frac{N+2}{2}}\right)}{2}\right. & \text { if } N \text { is even }\end{cases}
$$

We define a confidence interval for the median slope by calculating the lower limit denoted $\mathrm{P}_{\text {inf }}$ corresponding to $\mathrm{M}_{1}{ }^{\text {th }}$ and the upper limit denoted $\mathrm{P}_{\text {sup }}$ corresponding to $\left(M_{2}+1\right)^{\text {th }}$ of the $N$ ordered slope estimates; where $M_{1}$ and $\mathrm{M}_{2}$ are respectively given by (14) and (15):

$$
\begin{aligned}
& \mathrm{M}_{1}=\frac{\mathrm{N}-\mathrm{C}_{\alpha}}{2} \\
& \mathrm{M}_{2}=\frac{\mathrm{N}+\mathrm{C}_{\alpha}}{2}
\end{aligned}
$$

$\mathrm{C}_{\alpha}$ is the parameter calculated by (16):

$$
\mathrm{C}_{\alpha}=\left(\mathrm{Z}_{1-\frac{\alpha}{2}}\right) \sqrt{\operatorname{Var}(\mathrm{S})}
$$

Where $Z_{1-\frac{\alpha}{2}}$ and $\operatorname{Var}(S)$ are respectively the critical value of the test statistic $Z$ from the standard normal table for a desired significance level $\alpha$ and variance which is computed by (17):

$\operatorname{Var}(S)=\frac{1}{18}\left[n(n-1)(2 n+5)-\sum_{P=1}^{q}\left(t_{p}-1\right) t_{P}\left(2 t_{p}+5\right)\right]$

Where $q$ is the number of tied groups and $t_{p}$ is the number of data in the $\mathrm{p}^{\text {th }}$ group. The null hypothesis $\mathrm{H} 0$ (there is trend in the series) is accepted if we have:

$\mathrm{P}_{\text {inf }}<\mathrm{PM}<\mathrm{P}_{\text {sup }}$ if not, it is rejected. According to the magnitude and direction, a positive value of the median slope means that trend is upwards and its negative value means that trend is downwards.

\subsubsection{Mann-Kendall's Test}

Mann-Kendall's test is a non-parametric method, which is less sensitive to outliers and test for a trend in a time series without specifying whether the trend is linear or non-linear [54]. Mann-Kendall's test statistic is given as (18)

$$
\mathrm{S}=\sum_{\mathrm{i}=1}^{\mathrm{N}-1} \sum_{\mathrm{j}=\mathrm{i}+1}^{\mathrm{N}} \operatorname{sgn}\left(\mathrm{x}_{\mathrm{j}}-\mathrm{x}_{\mathrm{i}}\right)
$$

Where $\mathrm{S}$ is the Mann-Kendal's test statistics; $\mathrm{x}_{\mathrm{j}}$ and $x_{i}$ are the sequential data values of the time series in the years $\mathrm{i}$ and $\mathrm{j}(\mathrm{j}>\mathrm{i})$ and $\mathrm{N}$ is the length of the time series. A positive $S$ value indicates an increasing trend and a negative value indicates a decreasing trend in the data series. The sign function is given as (19):

$$
\operatorname{sgn}\left(x_{j}-x_{i}\right)=\left\{\begin{array}{c}
1 \text { if } x_{j}-x_{i}>0 \\
0 \text { if } x_{j}-x_{i}=0 \\
-1 \text { if } x_{j}-x_{i}<0
\end{array}\right.
$$

The variance of $\mathrm{S}$, for the situation where there may be ties (that is, equal values) in the $\mathrm{x}$ values is given by (20):

$\operatorname{Var}(S)=\frac{1}{18}\left[n(n-1)(2 n+5)-\sum_{i=1}^{m} t_{i}\left(t_{i}-1\right)\left(2 t_{i}+5\right)\right]$

Where $\mathrm{m}$ is the number of tied groups in the data set and $t_{i}$ is the number of data points in the $i^{\text {th }}$ tied group. For $n$ larger than $10, \mathrm{Z}_{\mathrm{MK}}$ approximates the standard normal distribution $[24,55]$ and computed as follows (21):

$$
Z_{\mathrm{MK}}=\left\{\begin{array}{l}
\frac{\mathrm{S}-1}{\sqrt{\operatorname{Var}(S)}} \text { if } \mathrm{S}>0 \\
0 \text { if } \mathrm{S}=0 \\
\frac{\mathrm{S}+1}{\sqrt{\operatorname{Var}(S)}} \text { if } \mathrm{S}<0
\end{array}\right.
$$

The presence of a statistically significant trend is evaluated using the $\mathrm{Z}_{\mathrm{MK}}$ value. In a two-sided test for trend, the null hypothesis Ho "there is no trend in the series", should be rejected if $\left|\mathrm{Z}_{\mathrm{MK}}\right|<\mathrm{Z}_{1-\frac{\alpha}{2}}$ (or $\mathrm{p}$-value $>\alpha$ ) at a given level of significance $\alpha$. The critical value $Z_{1-\frac{\alpha}{2}}$ of $\mathrm{Z}_{\mathrm{MK}}$ from the standard normal table. For example, for $\alpha=5 \%$ significance level, the value of $Z_{1-\frac{\alpha}{2}}$ is 1.96. A positive value of $\mathrm{Z}_{\mathrm{MK}}$ indicates an increasing trend while a negative value indicates a decreasing trend [28].

\section{Result and Discussion}

\subsection{Results of the Shifts Detection Tests}

We present the results of all shift detection tests in table2 and the corresponding graphics in (Fig 2). Both Pettitt test and Buishand test reject the null hypothesis of no shift at the $5 \%$ significance level for all stations. For these two tests, break occurs at year 1993 for Kédougou and Mako streamgauges, 1998 for Koulountou raingauge and 2002 for Diaguéri streamgauge. The Hubert's procedure of time series segmentation corroborates the preceding results and leads to the same years for break (Fig 3). We can conclude that the time series for all four stations (raingauge and streamgauge) are not homogeneous because they all have a shift. Nevertheless, the direction of the shift is not the same for all time series. The runoff increases for Mako and Diaguéri time series; it decreases for Kedougou streamgauge. The rainfall increases for Koulountou raingauge. 
Table 2. Homogeneity tests results; null hypothesis: absence of shift

\begin{tabular}{|c|c|c|c|c|}
\hline & Koulountou & Mako & Diaguiry & Kédougou \\
\hline Pettitt Test & |-------------- & |----------------- & |----------------- & ---------------- \\
\hline Test Result & $\mathrm{NO}$ & NO & $\mathrm{NO}$ & $\mathrm{NO}$ \\
\hline Break date & 1998 & 1993 & 2002 & 1993 \\
\hline Buishand Test & ------------ & --------------- & -------------- & ----------- \\
\hline Test Result & NO & $\mathrm{NO}$ & NO & $\mathrm{NO}$ \\
\hline Break date & 1998 & 1993 & 2002 & 1993 \\
\hline Hubert Test (order 2) & -------------- & ----------------' & ------------- & ------------ \\
\hline Test Result & NO & $\mathrm{NO}$ & NO & NO \\
\hline Break date & 1998 & 1993 & 2002 & 1993 \\
\hline
\end{tabular}

$\mathrm{NO}=$ Rejection of the null hypothesis

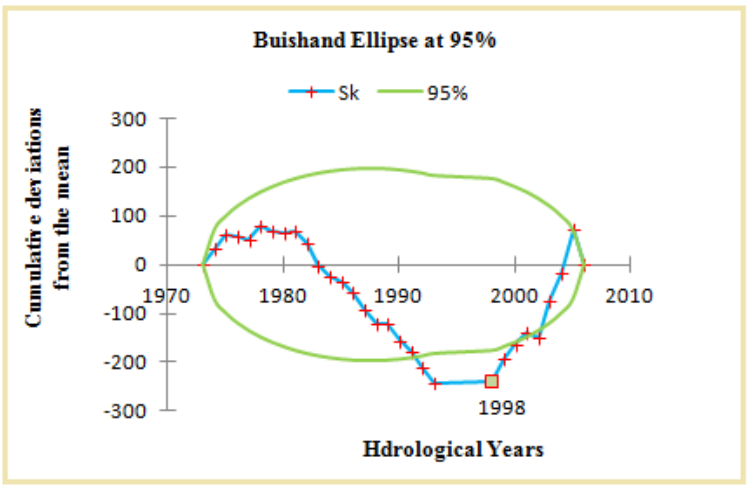

a)

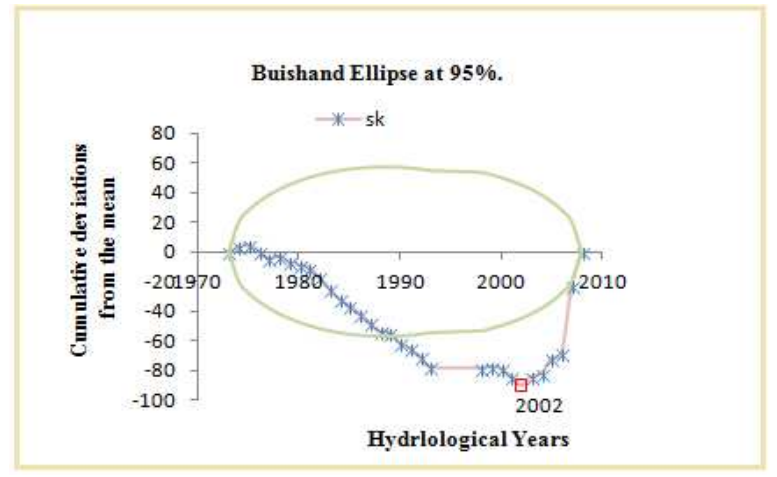

c)

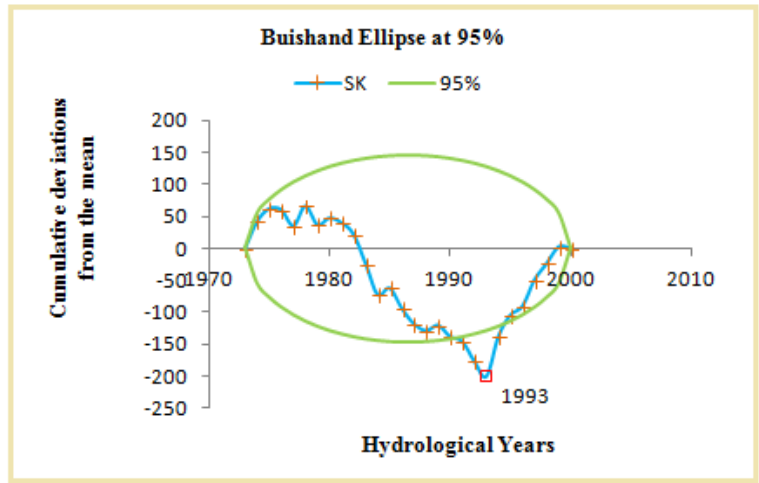

b)

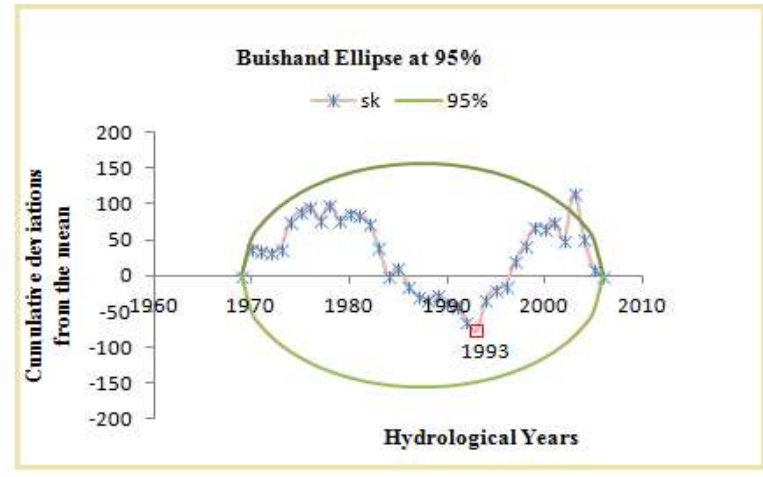

d)

Figure 2. Buishand ellipse on annual rainfall and runoff series

a) at Koulountou's Raingauge. b) at Mako's Streamgauge.

c) at Diaguéri Streamgauge. d) at Kedougou Streamgauge.

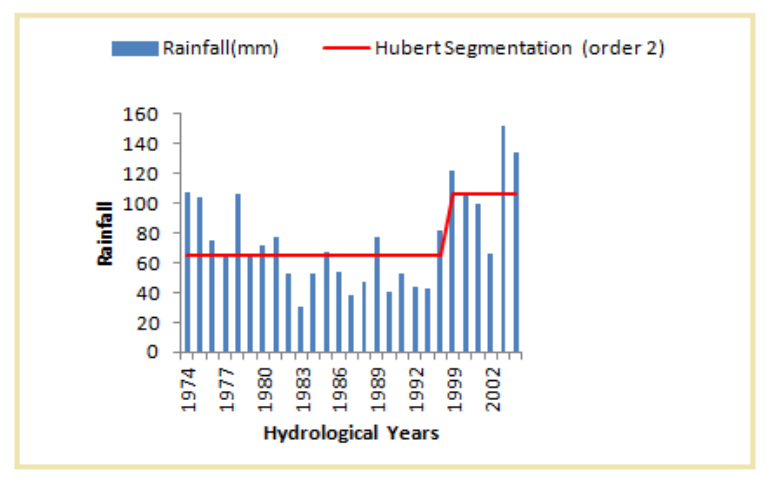

a)

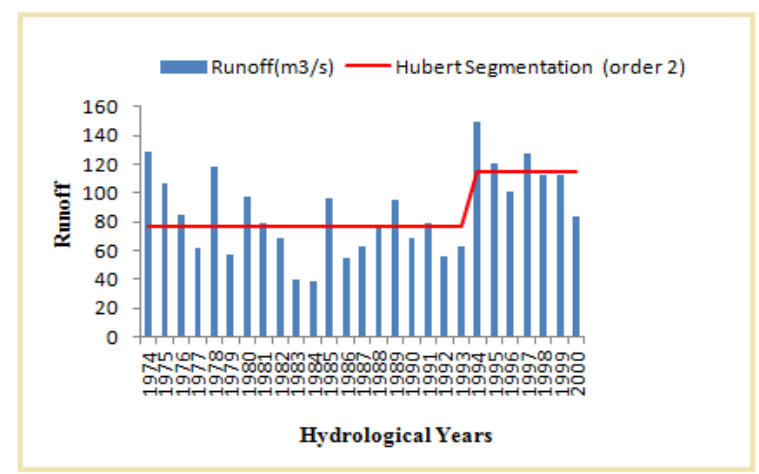

b) 


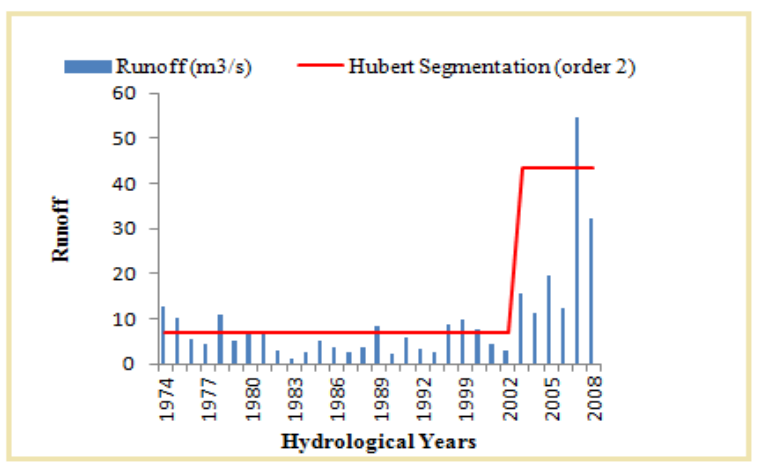

c)

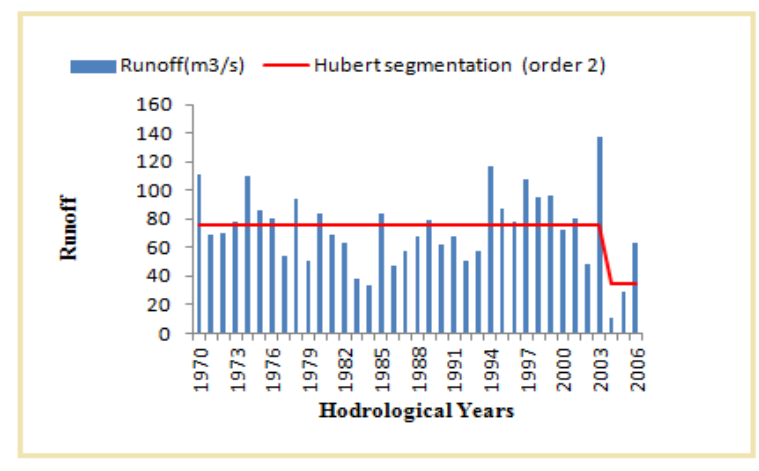

d)

Figure 3. Temporal evolution of rainfall and runoff series

a) at Koulountou's Raingauge. b) at Mako's Streamgauge.

c) at Diaguéri Streamgauge. d) at Kedougou Streamgauge.

\subsection{Results of the Trend Detection Methods}

The results of trend detection methods are indicated in Table3. According to this table, the Mann-Kendall test trend rejects the null hypothesis of no trend for all time series at $5 \%$ probability level. All time series present a trend. The value $\mathrm{Z}_{\mathrm{MK}}$ of the Mann Kendall are all positive

for Mako and Diaguéri runoff time series and for Koulountou rainfall time series. They are all negative for Kedougou runoff time series. This allows us to say that trend is upwards for Mako, Diaguéri and Koulountou, and downwards for Kedougou. The non parametric Sen's test is then applied to validate the Mann Kendall trend test and to estimate the magnitude of the trend and its direction. Sen's test rejects the null hypothesis of no trend for all time series for Mako, Diaguéri, Koulountou and Kedougou. The median slope is positive for Mako, Diaguéri and Koulountou time series, and negative for Kedougou time series. This means that trend is upwards for the first three gauges and downwards for the last. This is in adequation with the results of the Mann Kendall trend test.

Table 3. Summary of trend tests results, null hypothesis: absence of trend

\begin{tabular}{|c|c|c|c|c|}
\hline & Koulountou & Mako & Diaguéri & Kédougou \\
\hline Man-Kendall & 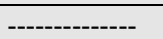 & ------------- & -------------- & ------------. \\
\hline Test Result & NO & NO & NO & NO \\
\hline SEN & ----- & ---- & ----- & $----\cdot$ \\
\hline Test Result & NO & NO & $\mathrm{NO}$ & $\mathrm{NO}$ \\
\hline
\end{tabular}

$\mathrm{NO}=$ Rejection of null hypothesis

\section{Conclusion}

The aim of the study is to detect any trends and/or shifts in the time series of the Gambia River Basin to highlight the effect of climate change and its impacts on the availability of the water resources of this basin. Non parametric tests have been applied: Pettitt, Hubert and Buishand tests for shifts detections, and Mann-Kendall test and Sen.'s method for trends and their direction and magnitude. These tests give the same results for shifts and trend detection. Time series present an upwards shift for runoff at Mako and Diaguéri streamgauge and rainfall at Koulountou raingauge, and downwards shift of runoff at Kedougou streamgauge. They indicate increasing trends for runoff at Mako and Diaguéri's streamgauges and for rainfall at Koulountou raingauge; and decreasing trends for runoff at Kedougou stream gauge. Trends and shifts in the time series are useful for water resources planning and management. However, it is important to keep in mind the limitations of the statistical approach used in this work. This approach doesn't indicate the physical processes underlying the shifts or trends. Complementary research are required to determinate the real cause of these phenomenon through climate models for example in order to better understand the relationship between climate variability and water resources.

\section{Acknowledgment}

We thank particularly Mr Lamine KONATE (Hydrologist, Project Coordinator of Integrated Management Resources Water in the watershed / river Geba Kayanga) from OMVG (Organization for the Development of the Gambia River) for putting data at our disposal within the framework of this study.

\section{References}

[1] Block P, Rajagopalan B (2007) « Interannual variability and ensemble forecast of upper Blue Nile basin kiremt season precipitation».Am.Meteorol.Soc.8:327-343. http://dx.doi.org/10.1175/JHM580.1

[2] KANOHIN F., SALEY M. B. et SAVANE I.,(2009) «Impacts of climate variability on water resources and human activities in the humid tropics: the case of the region Daoukro in Ivory Coast ». European Journal of Scientific Research, vol. 26, 2, p. 209-222

[3] Carmen Maftei, Alina Barbulescu, Constantin Buta, Cristina Serban; (2007) " Change Points Detection and Variability Analysis of some Precipitation Series ». Recent Researches in Computational Techniques, Non-Linear Systems and Control ISBN: 978-1-61804-011-4, 232-237 
[4] Emmanuel Amankwah; (2013) « Environmental Impact Assessment (EIA); A useful tool to address climate change in Ghana ». International Journal of Environmental Protection and Policy ; 1(4): 94-100

[5] Soussou Sambou1Yaya Diémé,Abdou Karim Touré,Ansou Malang Badji, Edmond Nicaise Malanda-Nimy,(2009) « Effect of Manantali on changes in the hydrological regime of the Senegal River in the upstream basin: a statistical approach » Sécheresse ; 20 (1): 104-111

[6] Ahoussi Kouassi Ernest, Koffi Yao Blaise, Kouassi Amani Michel, Soro Gbombélé, Soro Nagnin , Biémi Jean,(2013) «Study of hydroclimatic variability and its impact on water resources in South forestry and agricultural Côte d'Ivoire: the case of the Abidjan-Agboville region ». International Journal of Pure \& Applied Bioscience 1 (6): 30-50

[7] B. T. A. Goula, I. Savane, B. Konan, V. Fadika, G. B. Kouadio, (2006) «Impact of climate variability on water resources basins N'Zo N'Zi and Côte d'Ivoire (tropical Africa) ». Vertigo, 7 (1), 12p.

[8] Mertz O, C Mbow, Reenberg A, Diouf A (2009) « Farmers' perceptions of climate change and agricultural adaptation strategies in Rural Sahel ».ApproximatelyManage $43: 804-816$

[9] Hagos F, Makombe G, Namara RE, Awulachew SB (2009) «Importance of irrigated agriculture to the Ethiopian economy: Capturing the direct net benefits of irrigation. Colombo, Sri Lanka ».Int. Water Manage. Inst. pp. 37. (IWMI Research Report 128)

[10] A. B. Yao, B. T. A. Goula, Z. A. Kouadio, K. E. Kouakou, A Kane Et S. Sambou ; (2012) " Analysis Of Climate Variability And Quantification Water Resources in Tropical Wet Zone: From Watershed Case Of Lobo In Central West Of Ivory Coast ». Rev. Ivory. Sci. Technol, 19136 -. 157 ISSN 1813-3290, http://www.revist.ci

[11] J. E. Paturel, E. Servat, B. Kouame,J.F.Boyer, H. Lubes Niel,J.M.Masson,(1996) «Identification procedures "breaks" in time series - modification of rainfall in West Africa Sahel not. Tropical hydrology: Geoscience and development tool (Proceedings of the Paris Conference, May 1995) ». IAHS Publ. No. 238.1996. 99-110

[12] Soussou Sambou,(2004) « Statistical model heights of daily rainfall in the Sahel: the example of Senegal River basin upstream. » Hydrological Sciences Journal-of Hydrological Sciences, 49 (1); p115 -129

[13] Yann L'hote, Gil Mahé ,Bonaventure Some ,Jean Pierre Triboulet;2002 «Analysis of a Sahelian annual rainfall index from 1896 to 2000; the drought continues ». Hydrological Sciences-Journat-des Sciences Hydrologiques, 47(4) ; P563-572

[14] P. Hubert,J.C. Bader, H. Bendjoudi, 2007 « A Century of annual flows of the Senegal River, » Hydrological Sciences Journal, 52 (1), 2007, p. 68-73.

[15] C. Maftei, A. Barbulescu,(2008)« Statistical Analysis of Climate Evolution in Dobrudja Region. » Proceedings of the World Congress on Engineering 2008 Vol II WCE 2008, July 2-4, London, U.K.

[16] Bergaoui Mohamed,(2010)«Analysis Of Maximum Daily Rainfalls. Saida Manoubia Station,Tunis ».International Workshop Advances In Statistical Hydrology , 23-25,
Taormina, Italy

[17] S. Sahin and H.K. Cigizoglu,(2010) «Homogeneity analysis of Turkish meteorological data set ». Hydrol. Process. p1 -12

[18] Mohamed Talla CISSE, Soussou SAMBOU , Yaya DIEME, Clément DIATTA, Mamadou BOP, (2014) "Analysis of flows in the river basin Senegal From 1960 TO 2008 ISSN:. 1718-8598 ».Journal of Water Sciences 27 (2) (2014) $167-187$

[19] J. Suhaila, S. M. Deni, A. A. Jemain,(2008) « Detecting Inhomogeneity of Rainfall Series in Peninsular Malaysia. Asia-Pacific ». Journals of Atmospheric Sciences, 44, 4(2008),369-380

[20] Carmen Maftei, Alina Bărbulescu, Pierre Hubert, Cristina Serban, Gabriel Dobrica, (2009) «Statistical Analysis of the Precipitation from Constanța (Romania) Meteorological Station ». Recent Researches in Applied Computers and Computational Science. ISBN: 978-1-61804-084-8- P52-57

[21] J.R. Westmacott, D.H. Burn, 1997 « Climate change effects on the hydrologic regime within the Churchill-Nelson River Basin », J. Hydrol., 202, pp. 263- 279

[22] Awulachew SB, Erkossa T, Namara RE (2010) « Irrigation potential in Ethiopia: Constraints and opportunities for enhancing the system ». Report for IWMI

[23] X. Zhang, L.A. Vincent, W.D. Hogg, A. Niitsoo,(2000) « Temperature and precipitation trends in Canada during the 20th century ». Atmospheric Ocean, 38 , pp. 395-429

[24] T. Partal, E. Kahya, (2006) " Trend analysis in Turkey precipitation data ».Hydrologic Processes, 20, pp. 2011-2026, DOI: 10.1002/hyp.5993

[25] J.E. Paturel , I. Boubacar, A. L'aour,(2004) «Annual Rainfall Analysis In West And Central Africa During The 20 Th Century ». Sud Sciences \& Technologies $\mathrm{N}^{\circ} 13$ P40-46

[26] J. E. Paturel, E. Servat, M. O. Delattre ; H. Lubes-Niel,(1998) «Analysis of rainfall series of long-term West Africa and Sahel Central not in the context of climate variability». Hydrological Sciences Journal-of Hydrological Sciences, 43 (6), 937-946

[27] Manel Ellouze , Habib Abida, (2008) « Characterization of drought in southern Tunisia ». 13th World Water Congress . 1-4 September, Montpellier, France.1 P1-14

[28] Gebre Hadgu, Kindie Tesfaye, Girma Mamo and Belay Kassa,(2013) " Trend and variability of rainfall in Tigray, Northern Ethiopia: Analysis of meteorological data and farmers' perception ». Academia Journal of Environmental Sciences 1(8): 159-171, October 2013 http://www.academiapublishing.org/ajes ISSN: 2315-778X C2013 Academia Publishing

[29] N. Bru a, E. Biritxinaga a and F. D'Amico ,(2011) « Detection of significant changes in short time series: applications to the analysis of annual routines in behavioural ecology and to the analysis of breaks in abundance $»$. 19th International CongressonModelling and Simulation, Perth, Australia,12-16December2011http://mssanz.org.au/modsim 2011 P2211-2218

[30] G.J. McCabe Jr and D.M.Wolock,(1997) « Climate change and the detection of trends in annual runoff ». Clim. Res., 8 
[31] A.M.G. Klein Tank, F.W. Zwiers, and X. Zhang,(2009) "Guidelines on analysis of extremes in a changing climate in support of informed decisions for adaptation ». Technical Report 72, World Meteorological Organization.

[32] L. Xiong and S. Guo.(2004) «Trend test and change point detection for the annual discharge series of the Yangtze river at the Yichang hydrological station ». Hydrological Sciences Journal, 49(1):99-112.

[33] Renata Vezzoli, Silvano Pecora, Enrica Zenoni, Fabrizio Tonelli,(2012) « Data analysis to detect inhomogeneity, change points, trends in observations: an application to Po river discharge extremes CMCC ». Research Papers Issue RP0138; July 2012 Impact on Soil and Coasts Division (ISC P1-15)

[34] V.Ch. Khon, I.I. Mokhov, E. Roeckner, V.A. Semenov, (2007) «Regional changes of precipitation characteristics in Northern Eurasia from simulations with global climate model ».Global and Planetary Change, 57, , pp. 118-123

[35] Machiwal D, Jha MK.(2008) « Comperative evaluation of statistical tests for time series analysis: application to hydrologicaltimeseries».HydrologicalSciences,Journal-desS ciences Hydrologiques] 53(3): 353-366

[36] Helsel, D.R. and R. M. Hirsch, (2002) «Statistical Methods in Water Resources Techniques of Water Resources Investigations ».Book 4, chapter A3. U.S. Geological Survey, 522 pages

[37] C.Huntingford, R.G. Jones, C. Prudhomme, R. Lamb, J..H.C. Gash, D.A. Jones, (2003) « Regional climate model predictions of extreme rainfall for a changingclimate, Q. J. R. Meteorol. Soc., 129, pp. 1607-1621

[38] J.F. Boyer,(2002) « Logiciel Khronostat d'analyse statistique de series chronologique ». IRD UR2, Programme 21 FRIEND AOC, Equipe Hydrologie UMRGBE, Universite de Montpellier II, Ecole des Mines de Paris, 2002

[39] CAUSSINUS,H.,MESTRE,O.,(2004) « Detection and correction of artificial shifts in climate series ». Applied statistics, vol. 3, p. 405-425

[40] Ho Ming Kang and Fadhilah Yusof,(2012) « Homogeneity Tests on Daily Rainfall Series in Peninsular Malaysia ; Int. J. Contemp » . Math. Sciences, Vol. 7, 2012, no. 1, 9-22

[41] Ngongondo C, Yu-Xu C, Gottschalk L, Alemaw B (2011) « Evaluation of spatial and temporal characteristics of rainfall in Malawi: a case of data scarce region ». Theor. Appl. Climatol. DOI 10.1007/s00704-011-0413-0

[42] Kang HM, Yusof F (2012) " Homogeneity tests on daily rainfall series in Peninsular Malaysia. Int. J. Contemp. Math. Sci. 7(1):9-22.
[43] A. N. Pettitt,(1979) « A non-parametric approach to the change-point problem».Applied Statistics, 28 (2), pp.126-135

[44] Buishand, T. A. (1984): Tests for detecting a shift in the mean of hydrological time series ». Hydrol. 73, 51-69.

[45] A.A.Aka,E.Servat,J. E. Paturel \& B. Kouamé , H. Lubes, J. M. Masson,(1996) «Analysis of the temporal variabilityof runoff in Ivory Coast: statistical approach and phenomenacharacterization» .HydrologicalSciences-Journaldes Sciences Hydrologiques,41(6) December 959-970

[46] CostaAC,Soares A (2006): Identification of inhomogeneities in precipitation time series using SUR models and the Ellipse test. In: Caetano M, Painho M (eds.) Proceedings of Accuracy - 7th International Symposium on Spatial Accuracy Assessment in Natural Resources and Environmental Sciences.Instituto Geográfico Português, pp $419-428$

[47] P. Hubert, JP Carbonnel, (1993) « Segmentation annual series of major African rivers flow ». Binding CIEH Bulletin $92(3)$

[48] Hubert P. J.P.Carbonnel,A.Chaouche,(1989 ) « Segmentation of hydrometeorological series. Application to a series of precipitation and flow of West Africa ». Journal of Hydrology, 110, pp. 349-367

[49] P. Hubert, (2000) « The segmentation Procedure as a tool for Discrete Modeling of Hydrometeorological Regimes».Stochastic Environmental Research and Risk Assessment, 14 (4-5), pp. 297-304.

[50] Karpouzos Dk, Kavalieratou S, Babajimopoulos C (2010) "Trend analysis of Precipitation data in Pieria Region (Greece)». European Water. 30:31-40

[51] D.P.Lettenmaier, E.F. Wood, J.R. Wallis,(1994) «Hydroclimatological trends in the continental United States (1948-88) ». Journal of Climate, 7 , pp. 586-607

[52] Sen PK (1968) «Estimates of the regression coefficient based on Kendall's tau ». J. Am. Stat. Assoc. 39:1379-1389

[53] Ayalew D, Tesfaye K, Mamo G, Yitaferu B, Bayu W (2012) «Variability of rainfall and its current trend in Amhara region,Ethiopia».Afr.J.Agric.Res.7(10):1475-1486. http://dx.doi.org/10.5897/AJAR11.698

[54] Mann HB (1945) Mann HB (1945) « Non-parametric test against trend ». Econometrika 13:245-259

[55] Yenigun K, Gumus V, Bulut H (2008) «Trends in stream flow of the Euphrates basin, Turkey ». Proc. Inst. Civil Eng. Water Manage. 161:189-198.doi: 10.1680/wama.2008.161.4.189 